\title{
St. Gallen 2011: Summary of the Consensus Discussion
}

\author{
Michael Gnant $^{\mathrm{a}}$ Nadia Harbeck ${ }^{\mathrm{b}}$ Christoph Thomssen ${ }^{\mathrm{c}}$ \\ ${ }^{a}$ Comprehensive Cancer Center MUW/AKH, Universitätsklinik für Chirurgie, Medizinische Universität Wien, Austria \\ ${ }^{b}$ Brustzentrum, Klinik und Poliklinik für Frauenheilkunde und Geburtshilfe, Universitätsklinikum Köln, \\ 'Klinik und Poliklinik für Gynäkologie, Martin-Luther-Universität Halle-Wittenberg, Halle/Saale, Germany
}

\section{Keywords}

Early breast cancer - Bisphosphonates .

Endocrine therapy - Chemotherapy - Surgery .

Targeted therapy · Neoadjuvant therapy

\section{Summary}

The 2011 St. Gallen Consensus Conference on early breast cancer provided mostly evidence-based treatment recommendations with a broad spectrum of acceptable clinical practice for global breast cancer care. This report summarizes the results of the 2011 international panel voting procedures with regard to locoregional and endocrine treatment, chemotherapy, targeted therapy as well as adjuvant bisphosphonate use.

\section{Introduction}

The St. Gallen Consensus Conference 2011 (March 15-19) focussed again on therapy recommendations for early breast cancer that are based on evidence as well as clinical expertise of the international faculty, predominantly from Europe and the USA (table 1). For the first time, the panel openly disclosed any potential conflict of interest (www.oncoconferences.ch) and established a Conflict of Interest (COI) Committee chaired by Harold Burstein (Boston, MA, USA). Yet, it was recognized as being unavoidable that individual panel members have financial relationships with commercial organizations engaged in research, innovation, and education. $60 \%$ of the faculty declared potential conflicts of interests (range 1-12) with a median of 4.3 per panel member; none of these declared conflicts were judged to substantially impact the voting procedure and warrant exclusion of a panel member.

\author{
Schlüsselwörter \\ Frühes Mammakarzinom · Bisphosphonate . \\ Endokrine Therapie - Chemotherapie - Operation . \\ Zielgerichtete Therapie · Neoadjuvante Therapie
}

\section{Zusammenfassung}

Die diesjährige St. Gallen Konsensuskonferenz 2011 für das frühe Mammakarzinom gab im Wesentlichen evidenzbasierte Empfehlungen für die weltweite Behandlung mit einem breiten Spektrum an annehmbarer klinischer Praxis. Der vorliegende Bericht fasst die Abstimmungsergebnisse des internationalen Panels im Hinblick auf Lokaltherapie, endokrine Therapie, Chemotherapie, zielgerichtete Therapie und adjuvante Bisphosphonatgabe zusammen.

The motto of this year's conference was: 'Strategies for subtypes. Dealing with the diversity of breast cancer'. The Saturday morning consensus panel was chaired again by William Wood (Atlanta, GA, USA) and Aaron Goldhirsch (Lugano, Switzerland). Upfront, 10 areas of controversy (table 2) had been identified which deserved debate in order to agree on a range of solutions suitable for breast cancer care around the world. It was stated that clinical trials provide evidence that shows whether one treatment is better than another and help to estimate an average of outcome improvement, but not on how to treat an individual patient. The primary consideration on which the panel's voting decisions were based upon thus was to utilize tumour biology, host biology, and risk to obtain an optimal patient management strategy outside of a clinical trial that then still requires taking patient preferences into account. In 2011, the transition to the predominance of tumour biology rather than numerical

\section{KARGER \\ Fax +497614520714 \\ Information@Karger.de}

www.karger.com (c) 2011 S. Karger GmbH, Freiburg

$1661-3791 / 11 / 0062-0136 \$ 38.00 / 0$

Accessible online at:

www.karger.com/brc
Univ. Prof. Dr. Michael Gnant

Comprehensive Cancer Center MUW/AKH

Medizinische Universität Wien - Universitätsklinik für Chirurgie

Währinger Gürtel 18-20, 1090 Wien, Austria

Tel. +43 1 40400-5646, Fax -7603

michael.gnant@meduniwien.ac.at 
Table 1. Participants of the St. Gallen 2011 international breast cancer consensus panel (as announced in the conference program - not all were present at the voting process in St. Gallen)

\begin{tabular}{|c|c|}
\hline Participant & Country \\
\hline Matti Aapro & Switzerland \\
\hline Kathy Albain & USA \\
\hline Carlos H. Barrios & Brasil \\
\hline Josè Baselga & Spain \\
\hline Jonas Bergh & Sweden \\
\hline Hervè Bonnefoi & France \\
\hline Harold Burstein & USA \\
\hline Alan Coates & Australia \\
\hline Marco Colleoni & Italy \\
\hline Alberto Costa & Italy \\
\hline Nancy Davidson & USA \\
\hline Angelo Di Leo & Italy \\
\hline Bent Ejlertsen & Denmark \\
\hline John F. Forbes & Australia \\
\hline Richard D. Gelber & USA \\
\hline Agnes Glaus & Switzerland \\
\hline John H. Glick & USA \\
\hline Michael Gnant) & Austria \\
\hline Pamela Goodwin & Canada \\
\hline Jay R. Harris & USA \\
\hline Dan Hayes & USA \\
\hline James Ingle & USA \\
\hline Jacek Jassem & Poland \\
\hline Zefei Jiang & China \\
\hline Manfred Kaufmann & Germany \\
\hline Per Karlsson & Sweden \\
\hline Gunter von Minckwitz & Germany \\
\hline Monica Morrow & USA \\
\hline Moise Namer & France \\
\hline Larry Norton & USA \\
\hline C. Kent Osborne & USA \\
\hline Frédérique Penault-Llorca & France \\
\hline Charles Perou & USA \\
\hline Martine Piccart-Gebhart & Belgium \\
\hline Kurt Possinger & Germany \\
\hline Kathy Pritchard & Canada \\
\hline Emiel JT Rutgers & The Netherlands \\
\hline Vladimir Semiglazov & Russia \\
\hline Ian Smith & UK \\
\hline Beat Thürlimann & Switzerland \\
\hline Masakazu Toi & Japan \\
\hline Andrew Tutt & UK \\
\hline Michael Untch & Germany \\
\hline Giuseppe Viale & Italy \\
\hline Toru Watanabe & Japan \\
\hline Nicholas Wilcken & Australia \\
\hline Eric Winer & USA \\
\hline
\end{tabular}

disease indicators such as tumour size or extent of nodal involvement was finalized as shown by several votes of the panel.

In addition to the topics of gene signatures and systemic therapy covered in 2009 [1], St. Gallen 2011 also looked closely at controversial issues in locoregional therapy, taking recent data on sentinel node excision and intraoperative radiotherapy (RT) into account. In order to allow for an informative voting procedure, 100 questions had been preprepared and agreed on by the panellists. Three possible answers were allowed: yes/no/abstain. Abstain was to be used in
Table 2. Ten areas of controversy as discussed at the panel discussion in St. Gallen, Saturday March 19, 2011

$\begin{aligned} 1 & \text { Surgery: sentinel node } \\ 2 & \begin{array}{l}\text { Radiotherapy: ductal carcinoma in situ, accelerated, partial, post } \\ \text { mastectomy }\end{array} \\ 3 & \begin{array}{l}\text { Pathology: oestrogen receptor, progesterone receptor, HER2, } \\ \text { Ki-67, grade }\end{array} \\ 4 & \text { Multigene signatures } \\ 5 & \text { Endocrine therapies (esp. ovarian suppression, tamoxifen, } \\ & \text { aromatase inhibitors) } \\ 6 & \text { Chemotherapy (esp. anthracyclines, taxanes, platinum) } \\ 8 & \text { Targeted therapies } \\ 9 & \text { Neoadjuvant systemic therapies } \\ 10 & \text { Male breast cancer }\end{aligned}$

the case of insufficient data, no expertise on the particular issue, or conflict of interest. After each vote, the answers were summarized in percentages, adding up to $100 \%$. Only brief panel discussions were allowed on the key questions. This report summarizes the original voting questions and resulting percentages of the St. Gallen panel discussion on Saturday March 19, 2011. It may not be perfectly identical with the official St. Gallen publication that will appear later this year.

\section{Locoregional Therapy}

Locoregional treatment aspects were a major topic of this year's St. Gallen Consensus: While there was no change in technical aspects of primary tumour resection, the treatment of the axilla was a main focus, including but not limited to the question of axillary lymph node dissection (ALND) after sentinel node biopsy (SLND), mainly stimulated by the recent publication of the ACOSOG-011 data [2]. The validity of SLND itself was not even an issue during this year's panel discussion, reflecting the complete acceptance of this method in clinical practice. Following the report of ACOSOG-010 [3], the routine use of immunohistochemistry in order to look for low volume disease was declined by a majority of panel members ( $22 \%$ yes, $71 \%$ no). Also, completion ALND after isolated tumour cells (ITC) were found to be present in the sentinel node (SN) was rejected for mastectomy (6\% yes, $92 \%$ no) and breast conserving therapy ( $0 \%$ yes, $93 \%$ no).

In escalating the question of mandatory ALND after differential findings in the $\mathrm{SN}$ in patients with a clinically negative axilla, the panel clearly rejected ALND for ITCs in marginal sinus and body of the SN ( $2 \%$ yes, $98 \%$ no), for tumours less than $0.2 \mathrm{~mm}$ in size in a single SN ( $4 \%$ yes, $91 \%$ no), and - less unequivocally - for SN metastasis between 0.2 and $2 \mathrm{~mm}$ in size (19\% yes, $77 \%$ no). It appears noteworthy that this classification does not reflect the official UICC criteria $(<0.2 \mathrm{~mm}=$ micrometastasis, $0.2-2 \mathrm{~mm}=$ micrometastasis, and $>2 \mathrm{~mm}=$ macrometastases.

There was no direct vote on ALND after macrometastasis in the $\mathrm{SN}$, however, there was an intense and in part contro- 
versial discussion of the ACOSOG-011 data: Eventually, the panel concluded with broad majority that the Giuliano et al. [2] data must not be extrapolated to other patient groups than covered in that study. Besides several technical weaknesses of the ACOSOG study (only $50 \%$ of intended patients recruited $(\mathrm{n}=892)$, far less than the required number of events to show a difference, limited follow-up), only T1 and T2 patients with a clinically negative axilla (and systematic sonography of the axilla to confirm that) were included in that trial, and there was a clearly defined framework for the revolutionary concept of not doing ALND is those selected patients. Following clear statements by Monica Morrow, chief of breast surgery at the Memorial Sloan Kettering Cancer Centre, and the senior author of the study, the panel was clearly stating (71\% in support, $17 \%$ against) that this practice should not be extended to patients undergoing mastectomy, those who will not receive whole breast tangential field radiation therapy, those with involvement of 4 or more $\mathrm{SN}$, and patients receiving neoadjuvant therapy.

Not too many new aspects can be derived from the voting on mandatory RT after entirely excised ductal carcinoma in situ (DCIS) (68\% yes, 24\% no), possibility of avoidance of RT for DCIS in elderly (> 70 years) patients (58\% yes, 33\% no), and avoidance of RT in many patients with low grade/low risk DCIS (62\% yes, $32 \%$ no).

There was however a very clear statement of the panel endorsing accelerated whole breast RT (92\% yes, $4 \%$ no) following a recent report on a randomised trial with sufficient follow-up of patients treated with this new method [4]. The panel was divided whether standard RT should be the preferred option for extensive vascular invasion (34\% yes, $33 \%$ no).

There was also a controversial vote on whether intraoperative partial breast RT is acceptable as the definitive RT, without external beam RT ( $49 \%$ yes, 36\% no), whereas the majority endorsed intraoperative partial breast RT instead of external beam boost ( $62 \%$ yes, $23 \%$ no), as well as the use of any partial breast RT in selected (e.g. elderly $>70$ years) patients ( $87 \%$ yes, $7 \%$ no).

Routine postmastectomy RT was clearly endorsed for patients with more than 3 involved nodes ( $88 \%$ yes, $5 \%$ no), but declined for patients with 1-3 affected nodes (18\% yes, $71 \%$ no), unless maybe if they were young ( $<45$ years of age; $51 \%$ yes, $42 \%$ no) or presented with extensive vascular invasion (57\% yes, $26 \%$ no). Also, the panel did not support postmastectomy RT for large tumours $(\mathrm{T}>2)$ if node negative (13\% yes, $85 \%$ no).

\section{Prognostic and Predictive Factors}

According to this year's motto of the conference, molecular typing was discussed as an ideal model for how to define the heterogeneity of the disease. However, since for clinical routine genetic profiling is not yet established, immunohistochemical typing was still considered as state of the art for assessing risk of relapse and estimating the probable effect of specific therapy.

In 2005, St. Gallen divided tumour endocrine responsiveness into a highly responsive and an uncertain responsive category, looking at therapy targets rather than risk as the decisive criteria for therapeutic strategies [5]. In 2011, endocrine responsiveness was for the first time linked to the intrinsic molecular breast cancer subtypes suggested by Perou et al. $[6,7]$. Even though the terminology of luminal A vs. B tumours was used during the panel discussion, it was recognized that in the absence of a widely available standardized test system able to molecularly characterize these subtypes in clinical routine, immunohistochemical assessment of oestrogen receptor (ER) and progesterone receptor (PR) status should still be used. Addition of Ki-67 was suggested for defining proliferation and thus the difference between luminal $\mathrm{A}$ and $\mathrm{B}$ tumours but it became obvious from the discussion that no standardized methodology or cut-off definition for $\mathrm{Ki}-67$ is available so far. Eighty-five percent voted yes for the classification of luminal A tumours by ER, PR, negative HER2, and low Ki-67.

With regard to predictive factors for adjuvant chemotherapy, instead of providing a whole concept of when and how to indicate adjuvant chemotherapy, the panel discussed and voted upon single but practically relevant questions. Biological features were preferred as arguments against the pure extent of disease. Only $40 \%$ of the panellists considered nodal status as sufficient reason for giving adjuvant chemotherapy, whilst low differentiation (grade 3), HER2 overexpression, and lack of ER, PR and HER2 expression ('triple negative') were judged as clear arguments in favour of chemotherapy by more than $95 \%$ of the panellists. Having little evidence, the opinions about the following factors as argument for adjuvant chemotherapy were less uniform: only $69 \%$ voted for proliferation (Ki-67 (69\%), weak steroid hormone receptor expression i.e. $<50 \%$ ER-positive $(68 \%)$, and presence of lymphovascular invasion ( $40 \%$ in favour, $49 \%$ against) as factors that influence the decision for chemotherapy. In patients with extended lymph node involvement (more than 3 axillary lymph nodes tumour infiltrated), adjuvant chemotherapy was still considered as necessary by the majority (89\%).

Although during the entire meeting, molecular typing was considered as the adequate model representing the heterogeneity of breast cancers, it was not generally accepted for clinical decision making. Thus, only the multiparameter gene assay Oncotype DX ${ }^{\circledR}$ (Genomic Health Inc., Redwood City, CA, USA) was considered by a majority ( $84 \%$ ) as potentially useful for decision making upon adjuvant chemotherapy in cases where other factors (grade, HER2 etc.) do not help. On the other hand, the alternative test, the multigene array Mammaprint ${ }^{\circledR}$ (Agendia, Amsterdam, The Netherlands), was not accepted (69\% against). Also the option of using uPA/PAI-1 
as potential help in decision making was not accepted (23\% in favour, $50 \%$ against). Here, we would comment that arguments like practicability (need of fresh frozen tissue) potentially drove the voting, as the panel even denied the clear and published evidence for the clinical benefit from making use of uPA and PAI-1 [8-11].

\section{Endocrine Treatment}

Endocrine treatment is the first and oldest targeted therapy in breast cancer and considered a standard adjuvant therapy in all patients with endocrine-responsive tumours, i.e. immunohistochemical expression of ER and PR.

First, therapy recommendations for premenopausal patients were being discussed. Tamoxifen alone was still considered standard in premenopausal patients by the vast majority of the panel ( $94 \%$ yes). $83 \%$ (12\% no) thought that ovarian function suppression (OFS) plus tamoxifen was also a reasonable treatment for premenopausal patients, yet most panel members $(28 \%$ yes, $57 \%$ no) did not think that this option should be preferred. In extraordinary circumstances, OFS alone was still accepted ( $72 \%$ yes, $26 \%$ no). In the case of contraindicated tamoxifen, OFS + aromatase inhibitor (AI) was voted to be a therapeutic option ( $76 \%$ yes, $13 \%$ no).

For postmenopausal patients, there was a split vote $(50 \%$ yes, $50 \%$ no) for the question 'Should all postmenopausal patients receive an AI (at any time during therapy)?'. Yet, the majority (79\% yes, $21 \%$ no) thought that node-positive patients should receive an AI. If an AI was indicated, there was no clear preference whether to start it upfront or not with a vote of $41 \%$ yes and $52 \%$ no for the question: 'If an AI, need it be started upfront?'. $81 \%$ said yes $(12 \%$ no) to the question of a 5-year maximum AI duration: 'Is 5 years on AI sufficient for low-moderate risk postmenopausal patients?'. In agreement with the lack of evidence, $55 \%$ voted no ( $34 \%$ yes) to the question: 'Should more than 5 years AI be offered at present to postmenopausal patients with node-positive disease?', and $86 \%$ voted no (5\% yes) to 'Should more than 5 years AI be offered to postmenopausal patients $<55$ years irrespective of $\mathrm{N}$ status?'. 98\% agreed (2\% abstain) to switch to tamoxifen if patients are intolerant to AIs. The majority ( $89 \%$ yes, $11 \%$ no) also agreed that tamoxifen alone was still an option for postmenopausal patients ('Should any postmenopausal receive tamoxifen alone?').

In addition to the discussion of therapeutic decisions, predictive factors regarding the different endocrine therapy options were also discussed. Regarding CYP 2D6, the panel fully recognized the controversial evidence with recent negative results from large adjuvant trials presented at San Antonio $2010.96 \%$ denied ( $2 \%$ yes, $96 \%$ no) that CYP2D6 determination is important for the choice of endocrine therapy in postmenopausal women (AI vs. tamoxifen), and the same percentages were seen for this question regarding premeno- pausal patients ( $2 \%$ yes, $96 \%$ no, $2 \%$ abstain). Consequently, $98 \%$ declined ( $2 \%$ yes) that patients receiving tamoxifen should have CYP2D6 testing.

Regarding the choice of endocrine therapy in postmenopausal patients, the panel did not come to a conclusion $(48 \%$ yes, $52 \%$ no) on whether the choice between AI and tamoxifen should be dependent upon biological features (e.g. $\mathrm{N}+, \mathrm{Ki}-67$ ).

Positive HER2 status (overexpression, amplification) was generally accepted as an indication of adding chemotherapy to endocrine therapy ( $85 \%$ yes, $11 \%$ no). Yet, it was not accepted as an indication for AIs in postmenopausal patients ( $4 \%$ yes, $84 \%$ no) thus stating that HER2 status is not a predictive factor regarding the type of adjuvant endocrine therapy.

Lastly, obesity was not considered a general contraindication for AIs in postmenopausal patients (11\% yes, $76 \%$ no).

In the discussion of neoadjuvant therapy, 2 questions concerning neoadjuvant endocrine therapy were included. A vast majority ( $98 \%$ yes, $2 \%$ no) considered neoadjuvant endocrine therapy alone a reasonable option for postmenopausal patients with highly endocrine-responsive disease. This is more or less similar to the vote of 2009 (90\% yes, 7\% no). Regarding the duration, the panel members did not agree on any of the options: $3-4$ months (15\%), 4-8 months (39\%), or until maximal response (46\%). Compared to 2009 (20/49/37\%, respectively), most panel members now favoured endocrine neoadjuvant therapy until maximal response.

In summary, the voting results of St. Gallen 2011 regarding endocrine therapy clearly state that so far, only positive ER and PR status are decisive for the (neo-) adjuvant use of endocrine therapy and that there is no predictive tumour biological factor regarding choice of endocrine therapy. Tamoxifen alone is still considered standard in premenopausal patients, and both tamoxifen and AI are accepted options for the postmenopausal setting.

\section{Adjuvant Chemotherapy}

Interestingly, although doubting the clinical applicability of molecular typing, with regard to adjuvant chemotherapy many questions were focused on these originally gene-driven categories. Thus, the panellists voted upon luminal A cancers as less responsive to chemotherapy ( $86 \%$ ), and they could not define any single chemotherapy as preference for luminal A cancers $(84 \%)$. With regard to luminal B cancers, the majority recommended the use of anthracyclines (71\%) and taxanes $(63 \%)$. Also breast cancers with 'basal-like' phenotype should contain both, anthracyclines and taxanes (82\%). Some questions focused on triple-negative breast cancer (TNBC). The majority supported the use of alkylating agents like cyclophosphamide (93\%) in TNBC, but voted against experimental approaches like adding platinum salts (64\%) 
and anti-angiogenic drugs (88\%). About half of the panellists $(52 \%)$ considered dose-dense chemotherapy for triple-negative tumours.

\section{Trastuzumab}

Substantial attention was given to the issue of adjuvant therapy of HER2-overexpressing cancers. Consistently, most panellists did not prefer a special chemotherapy regimen $(57 \%)$, and a clear majority voted for the use of anthracyclines $(75 \%)$ and taxanes $(83 \%)$ in HER2-positive disease. All panellists $(100 \%)$ considered trastuzumab therapy (concurrent or following chemotherapy) over 1 year as standard in HER2-positive phenotype, it was also recommended for tumours between 5 and $10 \mathrm{~mm}$ (79\%). Interestingly, in very small tumours (pT1a) the majority $(61 \%)$ would not recommend trastuzumab therapy. It was discussed whether trastuzumab could be given with less chemotherapy (e.g. 12 weekly courses of paclitaxel); having no data, the panellists refused to vote on this question. However, they accepted trastuzumab alone with or without adjuvant endocrine therapy if chemotherapy is contraindicated (67\%), although in general trastuzumab alone ( \pm endocrine therapy) was not considered as an appropriate adjuvant treatment (78\%).

With regard to the treatment sequence, the majority preferred the application of trastuzumab concurrently with chemotherapy (86\%). However, sequential treatment was also accepted as an option (84\%). Overall, if easy access to the drug is given, therapy shorter than 1 year was not accepted as standard (63\%); on the other hand, in the case of limited resources, shorter duration may be an option (71\%). Obviously, without data, adjuvant trastuzumab therapy over more than 1 year was not accepted as standard treatment $(84 \%)$.

\section{Neoadjuvant Chemotherapy}

Whilst in St. Gallen 2009, neoadjuvant systemic therapy was not a major focus, this year some attention was drawn to the major questions of this approach. Many panellists (60\%) felt that alteration of surgical therapy should not be the only reason for choosing the neoadjuvant therapy approach but the majority would use it most likely for this purpose (73\%). It is well accepted that neoadjuvant chemotherapy is not a sensible option in patients with low proliferating (Ki-67 < 14\%) cancers $(64 \%)$ and in highly endocrine-responsive disease (77\%) such as 'classical' pure type lobular cancer (HER2-negative, grading 1-2, hormone receptor-positive).

Neoadjuvant chemotherapy should contain anthracyclines $(82 \%)$ and taxanes $(89 \%)$. Standard adjuvant chemotherapy regimens can be used in the neoadjuvant indication $(82 \%)$, and in HER2-overexpressing tumours neoadjuvant regimens should also contain anti-HER2 medication (87\%). Although interesting data were presented [12,13], dual HER2-targeting is currently not accepted as a reasonable therapy option in HER2-positive disease (67\%).

With regard to highly endocrine-responsive disease in postmenopausal patients, neoadjuvant endocrine therapy was highly accepted as a reasonable option (98\%). However, the ideal duration seems to be unclear, most voted for 4-8 months $(39 \%)$.

\section{Bisphosphonates}

With respect to adjuvant bisphosphonates, the panel did not vote on the bone-protective effects of these agents since the usefulness of bone-targeted treatments for this purpose is already clearly established. With respect to the anti-cancer effects of adjuvant zoledronic acid, there was some discussion following the thought-provoking but overall non-confirmatory presentation of the AZURE trial [14]. Even in view of large phase III clinical trials in patients with endocrineresponsive breast cancer both in the premenopause [15] and after the menopause [16], the panel did not support the general use of bisphosphonates for anti-tumour effect in premenopausal patients irrespective of ovarian function suppression (11\% yes, $81 \%$ no) nor postmenopausal patients during adjuvant endocrine treatment ( $21 \%$ yes, $72 \%$ no).

The panel did not endorse the fact that zoledronic acid given every 6 months during endocrine therapy improves disease-free survival (23\% yes, $65 \%$ no); however, the panel was divided with respect to the existence of such an effect in a low-oestrogen environment (33\% yes, $44 \%$ no). The panel clearly declined that denosumab should substitute zoledronic acid ( $2 \%$ yes, $83 \%$ no).

\section{Male Breast Cancer}

This year, the St. Gallen committee again commented on the therapy of male breast cancer. All male patients with ER-positive breast cancer should receive adjuvant tamoxifen $(85 \%)$. AIs were considered as an optional alternative by $54 \%$ of the panellists if contraindications to tamoxifen are present. Some discussion was raised upon the issue whether the standard dose would be sufficient with regard to high aromatase concentrations in the testes. Reflecting the insufficient data, it remains unclear whether AIs should be given as extended adjuvant endocrine treatment in node-positive male breast cancer ( $28 \%$ yes, $41 \%$ no, $31 \%$ abstain). 


\section{Conclusion}

St. Gallen 2011 was a very efficiently run consensus panel discussion, providing international expert opinions on 100 therapeutically relevant questions for early breast cancer. As demonstrated by the very few unanimous votes, international breast cancer therapy concepts are based on evidence, clinical expertise, as well as availability of certain diagnostic or therapeutic procedures in individual countries. The St. Gallen consensus panel recommendations thus provide a minimal standard for up-to-date breast cancer treatment from which national guidelines may well differ. For example, the National Comprehensive Cancer Network (NCCN) provides widely accepted expert guidelines for the USA (www.nccn.org).
For Germany, the annually updated Arbeitsgemeinschaft Gynäkologische Onkologie (AGO) guidelines (www.agoonline.de) that systematically review recent peer-reviewed publications and abstracts from the major international breast cancer conferences such as American Society of Clinical Oncology (ASCO) or San Antonio (SABCS) thus provide a practical framework for evidence-based breast cancer therapy.

\section{Disclosure Statement}

The authors declare no conflict of interest.

\section{References}

1 Goldhirsch A, Ingle JN, Gelber RD, et al.: Thresholds for therapies: highlights of the St Gallen International Expert Consensus on the primary therapy of early breast cancer 2009. Ann Oncol 2009;20:1319-29.

2 Giuliano AE, Hunt KK, Ballman KV, et al. Axillary dissection vs no axillary dissection in women with invasive breast cancer and sentinel node metastasis. JAMA 2011;305:569-75.

>3 Krag DN, Anderson SJ, Julian TB, et al.: Sentinellymph-node resection compared with conventional axillary-lymph-node dissection in clinically nodenegative patients with breast cancer: overall survival findings from the NSABP B-32 randomised phase 3 trial. Lancet Oncol 2010;11:927-33.

4 Whelan TJ, Pignol JP, Levine MN, et al.: Longterm results of hypofractionated radiation therapy for breast cancer. N Engl J Med 2010;362:513-20.

$\checkmark 5$ Goldhirsch A, Coates AS, Gelber RD, et al.: First - select the target: better choice of adjuvant treatments for breast cancer patients. Ann Oncol 2006;17:1772-6.

6 Perou CM, Sørlie T, Eisen MB, van de Rijn M, Jeffrey SS, Rees CA, Pollack JR, Ross DT, Johnsen H, Akslen LA, Fluge O, Pergamenschikov A, Williams C, Zhu SX, Lønning PE, Børresen-Dale AL, Brown PO, Botstein D: Molecular portraits of human breast tumours. Nature 2000;406:747-52.
7 Sørlie T, Perou CM, Tibshirani R, Aas T, Geisler S, Johnsen $H$, Hastie $T$, Eisen MB, van de Rijn M, Jeffrey SS, Thorsen T, Quist $\mathrm{H}$, Matese JC, Brown PO, Botstein D, Eystein Lønning P, Børresen-Dale AL: Gene expression patterns of breast carcinomas distinguish tumour subclasses with clinical implications. Proc Natl Acad Sci U S A 2001;98:10869-74.

8 Jänicke F, Prechtl A, Thomssen C, Harbeck N, Meisner C, Untch M, Sweep CG, Selbmann HK, Graeff H, Schmitt M; German No Study Group: Randomized adjuvant chemotherapy trial in highrisk, lymph node-negative breast cancer patients identified by urokinase-type plasminogen activator and plasminogen activator inhibitor type 1 . J Natl Cancer Inst 2001;93:913-20

9 Harbeck N, Kates RE, Look MP, Meijer-Van Gelder ME, Klijn JG, Krüger A, Kiechle M, Jänicke F, Schmitt M, Foekens JA: Enhanced benefit from adjuvant chemotherapy in breast cancer patients classified high-risk according to urokinase-type plasminogen activator (uPA) and plasminogen activator inhibitor type $1(\mathrm{n}=3424)$. Cancer Res 2002;62:4617-22.

10 Thomssen C, Harbeck N, Dittmer J, AbrahaSpaeth SR, Papendick N, Paradiso A, Lisboa B, Jaenicke F, Schmitt M, Vetter M: Feasibility of measuring the prognostic factors UPA and PAI-1 in core needle biopsy breast cancer specimens. J Natl Cancer Inst 2009;101:1028-9.

11 Harbeck N, Thomssen C: A new look at nodenegative breast cancer. Oncologist 2011;16 (suppl 1):51-60, review.
12 Baselga J, Bradbury I, Eidtmann H, Di Cosimo S, Aura C, De Azambuja E, Gomez H, Dinh P, Fauria K, Van Dooren V, Paoletti P, Goldhirsch A, Chang T-W, Lang I, Untch M, Gelber RD, Piccart-Gebhart M, on behalf of the NeoALTTO study team: First results of the NeoALTTO tria (BIG 01-06 / EGF 106903): a phase III, randomized, open label, neoadjuvant study of lapatinib, trastuzumab, and their combination plus paclitaxel in women with HER2-positive primary breast cancer. SABS, Texas, 2010, abstr S3-3.

13 Gianni L, Pienkowski T, Im Y-H, Roman L, Tseng L-M, Liu M-C, Lluch-Hernandez A, Semiglazov V, Szado T, Ross G: Neoadjuvant pertuzumab $(\mathrm{P})$ and trastuzumab $(\mathrm{H})$ : antitumor and safety analysis of a randomized phase II study ('NeoSphere'). SABS, Texas, 2010, abstr S3-2.

14 Coleman R, Thorpe H, Cameron D, et al.: Adjuvant treatment with zoledronic acid in stage II/ III breast cancer. The AZURE trial (BIG 01/04). Cancer Res 2010;70(24 suppl):abstr S4-5.

15 Gnant M, Mlineritsch B, Schippinger W, et al.: Endocrine therapy plus zoledronic acid in premenopausal breast cancer. $\mathrm{N}$ Engl J Med 200912;360:679-91.

16 Eidtmann $\mathrm{H}$, de Boer R, Bundred N, et al.: Efficacy of zoledronic acid in postmenopausal women with early breast cancer receiving adjuvant letrozole: 36-month results of the ZO-FAST Study. Ann Oncol 2010;21:2188-94. 